\title{
Gambaran klinis dan faktor predisposisi dari coated tongue pada mahasiswa gigi klinik Fakultas Kedokteran Gigi Universitas Padjadjaran
}

\author{
Meelaashah Ragunathan', Erna Herawati², Lusi Epsilawati ${ }^{3 *}$
}

\begin{abstract}
Objectives: The aim of this research is to find the clinical features and the predisposing factors of coated tongue among clinical dental students in Faculty of Dentistry Universitas Padjadjaran.

Material and Methods: The research is a descriptive type where students with coated tongue were observed and specific scores were given based on Miyazaki classification and Gomez classification to measure the distribution and discoloration of the coating on the tongue. For the predisposing factor, a questionnaire was given out to find out the most influential predisposing factor.

${ }^{1}$ Program Studi Pendidikan Dokter Gigi, Fakultas Kedokteran Gigi, Universitas Padjadjaran, Bandung, Indonesia, 40132

${ }^{2}$ Departemen IImu Penyakit Mulut Fakultas Kedokteran Gigi, Universitas Padjadjaran, Bandung, Indonesia, 40132

Departemen Radiologi Kedokteran Gigi, Fakultas Kedokteran Gigi, Universitas Padjadjaran, Bandung, Indonesia, 40132

*Correspondence to:

Lusi Epsilawati

凶lusifkg92@gmail.com
Results: In this research, 68 clinical dental students were found with coated tongue. Based on Miyazaki classification, 28 have score 1, 29 have score 2 and

\section{PENDAHULUAN}

Lidah yang juga dikenal sebagai lingua atau glossal, adalah organ berotot yang terletak di dasar mulut di mana ia membantu dalam mengunyah menelan, berbicara, dan sebagainya. ${ }^{1,2,3}$ Permukaan lidah dapat dibagi menjadi permukaan dorsal, ventral, dan lateral. Permukaan dorsal lidah adalah epitel keratinisasi skuamosa berlapis. Ditutupi oleh berbagai proyeksi mukosa yang disebut papila. ${ }^{2}$ Secara alami, lidah dilapisi dengan sel-sel epite mati tetapi akan dikeluarkan dari lidah dengan membersihkan lidah dan gesekan antara makanan dan lidah. Gagal melakukannya, sebuah plak tipis tetap berada di permukaan dorsal lidah dan ini akan menjadi tempat bagi bakteri anaerob untuk mendegradasi substrat organik dan menyebabkan bau busuk. Coated tongue biasanya tampak putih tetapi mungkin tampak berbeda karena makanan kromogenik. Misalnya, mereka bisa berwarna cokelat atau kuning. Sebagian besar, lapisan terkonsentrasi pada sisi posterior lidah. ${ }^{2}$

Menurut Survei Pemeriksaan Kesehatan dan Gizi Nasional, lidah adalah situs oral yang paling umum terkena sedangkan lidah menempati urutan kedua setelah mukosa labial. Prevalensi lesi lidah ditemukan pada sekitar 15,5 persen pada orang
11 have score 3. Based on Gomez classification 63 have score 1 (92.6\%), 3 have score 2 (4.4\%) and 2 have score 3 (3\%). coated tongue occur due to soft diet on 29 students (42.6\%), medication intake on four students (5.9\%), less water intake on 26 students (38.2\%) and less fiber intake on nine students (13.2\%).

Conclusion: Among all clinical dental students in Faculty of Dentistry Universitas Padjadjaran, most of the sample have scored 2 for Miyazaki classification and score 1 for Gomez classification. For the predisposing factors, coated tongue highly occured due to soft diet followed by less water intake, less fiber intake and medication intake.
Keywords: Coated tongue, clinical features, predisposing factor

Cite this article: Ragunathan M, Herawati E, Epsilawati L. Gambaran Klinis dan Faktor Predisposisi dari Coated Tongue pada Mahasiswa Gigi Klinik Fakultas Kedokteran Gigi Universitas Padjadjaran. Jurnal Radiologi Dentomaksilofasial Indonesia 2019;3(3)17-20. https://doi.org/10.32793/jrdi.v3i3.441 dewasa di Amerika Serikat. ${ }^{4}$ Selain itu di Maharashtra Barat, India dari 1500 pasien rawat jalan, 16,1\% didiagnosis dengan lesi lidah ketika penelitian prospektif dilakukan. Berdasarkan analisis tentang prevalensi lesi lidah di Fakultas Kedokteran Gigi di Jordan University, 11,5\% memiliki lidah dilapisi (8,2\%)., ${ }^{5,6}$ Di Asia, sebuah penelitian telah dilakukan untuk memeriksa prevalensi lesi mukosa mulut di India. Hasilnya coated tongue memiliki prevalensi tertinggi $(28,0 \%)$ dibandingkan dengan lesi lidah lainnya. ${ }^{7}$ Sementara itu, prevalensi coated tongue dilaporkan sebesar $8,2 \%$ dalam penelitian yang dilakukan oleh Darwazeh et al. dalam populasi Yordania. Prevalensi coated tongue pada populasi India jauh lebih tinggi daripada penelitian lain. Penelitian serupa pada populasi Turki, lesi ini merupakan lesi yang paling umum tetapi prevalensinya sangat rendah $(2,1 \%)^{6,8}$

Lesi ini dapat didiagnosis secara klinis. Beberapa klasifikasi untuk mengklasifikasikan dan mencetak lapisan pada lidah. Namun, untuk penelitian ini, klasifikasi Miyazaki dan klasifikasi Gomez digunakan untuk mengukur pelapisan lidah. Klasifikasi Miyazaki digunakan dalam penelitian ini karena statusnya didasarkan pada distribusi lapisan pada 
permukaan dorsal lidah. $^{9}$ Dengan demikian, klasifikasi Gomez digunakan untuk menggambarkan lapisan pada permukaan dorsal lidah berdasarkan perubahan warna. Tidak ada penelitian yang menyatakan korelasi antara fitur klinis dan faktor predisposisi. $^{9}$

Berdasarkan data di atas, semua data didasarkan pada populasi umum. Sebelumnya, penulis telah melakukan penelitian tentang prevalensi lesi lidah di kalangan mahasiswa Fakultas Kedokteran Gigi Universitas Padjadjaran (FKG Unpad) dan coated tongue memiliki prevalensi tertinggi kedua yaitu $27,2 \%{ }^{10}$ Penelitian ini dilakukan pada populasi yang sama yang memiliki coated tongue. Oleh karena itu, tujuan dari penelitian ini adalah untuk menemukan fitur klinis dan faktor predisposisi yang paling berpengaruh dalam kasus coated tongue di FKG Unpad.

\section{BAHAN DAN METODE}

Penelitian ini adalah penelitian tipe deskriptif dimana mahasiswa dengan coated tongue dari tahun 2016 hingga 2018 mahasiswa kedokteran gigi di FKG Unpad menggunakan total sampling. Izin etik diperoleh dari Komite Etik Kelembagaan Fakultas Kedokteran Unpad. Surat persetujuan diberikan oleh Rumah Sakit Gigi dan Mulut Unpad untuk menggunakan kursi gigi. Prosedur penelitian ini dijelaskan kepada subyek dan subyek menandatangani pernyataan persetujuan setelah mereka memahami dan setuju untuk berpartisipasi. Subjek akan duduk di kursi gigi. Subjek diperiksa dari pandangan punggung.

Data subjek penelitian dengan coated tongue diperoleh melalui observasi langsung berdasarkan penampilan klinis. Skor untuk lapisan lidah diberikan berdasarkan klasifikasi Miyazaki. Nilai 0 diberikan ketika lapisan tidak terlihat, skor 1 diberikan ketika kurang dari sepertiga dari permukaan punggung tertutup, skor 2 ketika kurang dari dua pertiga dari permukaan punggung tertutup dan skor 3 diberikan ketika lapisan lidah tertutup lebih dari dua pertiga permukaan dorsal lidah. Untuk klasifikasi Gomez, skor 0 diberikan ketika lapisan tidak berwarna, skor 1 diberikan ketika lapisan putih, skor 2 ketika lapisan berwarna kuning, skor 3 diberikan ketika lapisan lidah berwarna coklat dan skor 4 diberikan saat lapisannya berwarna hitam. Skor 0 tidak termasuk tetapi skor 1 hingga 3 untuk klasifikasi Miyazaki dan skor 1 hingga 4 untuk klasifikasi Gomez dicatat dalam lembar tabulasi. Gambar lesi akan diambil untuk dokumentasi.

Kuisioner online diisi untuk mengetahui faktorfaktor predisposisi. Coated tongue dapat memiliki banyak predisposisi, pada penelitian ini dikategorikan sebagai berikut, diet lunak, asupan air lebih sedikit, asupan serat lebih sedikit dan penggunaan obat-obatan tertentu. Diet lunak diartikan sebagai pola diet yang melibatkan sistem fungsi pengunyahan minimal pada individu. Asupan air yang lebih sedikit adalah ketika subyek minum kurang dari jumlah optimal kacamata (delapan gelas per hari) dalam sehari. Sedangkan asupan serat yang lebih sedikit adalah saat subjek tidak memasukkan sayur dalam makanan sehari-hari. Obat adalah ketika subjek penelitian mengkonsumsi antibiotik atau obat imunosupresan yang berkontribusi pada coated tongue.

\section{HASIL}

Tabel 1. Frekuensi coated tongue berdasarkan jenis kelamin

\begin{tabular}{ccc}
\hline Coated Tongue & $\begin{array}{c}\text { Jumlah } \\
\text { Sampel }\end{array}$ & Persentase \% \\
\hline Laki-laki & 7 & 10.3 \\
Perempuan & 61 & 89.7 \\
\hline Total & 68 & 100 \\
\hline
\end{tabular}

Penelitian ini dilakukan terhadap 68 mahasiswa klinik gigi yang ditemukan dengan coated tongue. Dari 68 mahasiswa kedokteran gigi klinis, 61 adalah perempuan (89,7\%) dan 7 adalah laki-laki $(10,3 \%)$ (Tabel 1). Juga, berdasarkan klasifikasi Miyazaki, didapatkan sebanyak 28 sampel memiliki skor 1 $(41,2 \%), 29$ sampel memiliki skor $2(42,6 \%)$ dan 11 sampel dengan skor $3(16,2 \%)$ (Tabel 2). Tabel 3 menunjukkan hasil pengukuran pelapisan (coating) pada lidah berdasarkan perubahan warna atau diskolorasi oleh klasifikasi Gomez, dimana sebanyak
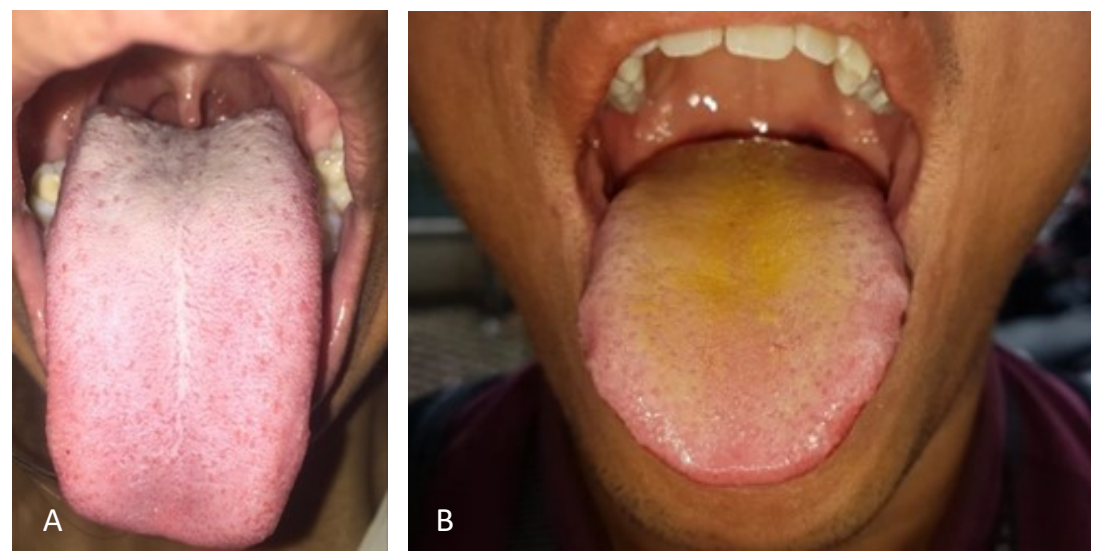

Gambar 1. Beberapa gambaran coated tongue yang ditemukan pada sampel penelitian, (A) Coated tongue dengan skor 3 (klasifikasi Miyazaki); (B) coated tongue dengan skor 2 (klasifikasi Gomez) 


\begin{tabular}{ccccccc}
\hline \multirow{2}{*}{ Skor } & \multirow{2}{*}{$\begin{array}{c}\text { Jumlah } \\
\text { Sampel }\end{array}$} & \multirow{2}{*}{$\begin{array}{c}\text { Persentase } \\
\%\end{array}$} & & \multicolumn{5}{c}{ Jenis Kelamin } \\
\cline { 4 - 7 } & & & Laki-laki & $\%$ & Perempuan & $\%$ \\
\hline 1 & 28 & 41.2 & 4 & 57.1 & 47 & 77 \\
2 & 29 & 42.6 & 2 & 28.6 & 10 & 16.4 \\
3 & 11 & 16.2 & 1 & 14.3 & 4 & 6.6 \\
\hline Total & 68 & 100 & 7 & 100 & 61 & 100 \\
\hline
\end{tabular}

Tabel 2. Hasil penilaian coating tongue berdasa kan area (Miyazaki)

\begin{tabular}{ccccccc}
\hline \multirow{2}{*}{ Skor } & \multirow{2}{*}{$\begin{array}{c}\text { Jumlah } \\
\text { Sampel }\end{array}$} & \multirow{2}{*}{$\begin{array}{c}\text { Persentase } \\
\%\end{array}$} & & \multicolumn{5}{c}{ Jenis Kelamin } \\
\cline { 4 - 7 } & & & Laki-laki & $\%$ & Perempuan & $\%$ \\
\hline 1 & 63 & 4.6 & 4 & 57.1 & 59 & 96.7 \\
2 & 3 & 3 & 1 & 28.6 & 2 & 0.3 \\
3 & 2 & - & 2 & 14.3 & - & - \\
4 & - & 100 & 7 & 100 & 61 & - \\
\hline Total & 68 & & & & & \\
\hline
\end{tabular}

Tabel 3. Hasil penilaian coating tongue berdasa kan diskolorasi (Gomez)

\begin{tabular}{ccccccc}
\hline \multirow{2}{*}{ Faktor Predisposisi } & \multirow{2}{*}{$\begin{array}{c}\text { Jumlah } \\
\text { Sampel }\end{array}$} & $\begin{array}{c}\text { Persentase } \\
\%\end{array}$ & & \multicolumn{4}{c}{ Jenis Kelamin } \\
\cline { 4 - 7 } & & 42.6 & Laki-laki & $\%$ & Perempuan & $\%$ \\
\hline Soft Diet & 29 & 38.2 & - & 42.9 & 26 & 42.6 \\
Less water intake & 26 & 13.2 & 2 & 28.6 & 7 & 42.6 \\
Less fiber intake & 9 & 5.9 & 2 & 28.6 & 2 & 11.5 \\
Medication intake & 4 & 100 & 7 & 100 & 61 & 100 \\
\hline Total & 68 & & &
\end{tabular}

Tabel 4. Hasil persebaran faktor predisposisi berdasarkan hasil pengisian hasil pengisian kuisoner

63 sampel memiliki skor 1 (92,6\%), 3 sampel memiliki skor $2(4,4 \%)$ dan 2 sampel memiliki skor 3 (3\%)Dalam penelitian ini, coated tongue diduga terjadi karena beberapa faktor predisposisi. Hasi pengisian kuisioner menunjukkan beberapa hal yang diduga dapat menjadi faktor predisposisi yang paling berpengaruh pada tiap individunya, antara lain seperti kebiasaan diet lunak pada 29 sampel $(42,6 \%)$, asupan obat pada 4 sampel $(5,9 \%)$, asupan air lebih sedikit pada 26 sampel $(38,2 \%)$ dan kurang asupan serat pada 9 sampel $(13,2 \%)$ (Tabel 4).

\section{DISKUSI}

Tujuan dari penelitian ini adalah untuk menemukan fitur klinis dan faktor predisposisi dar kasus coated tongue yang ditemukan di antara mahasiswa kedokteran gigi klinik FKG Unpad. Dalam penelitian ini, sebagian besar sampel dengan coated tongue adalah perempuan, karena mayoritas mahasiswa di RSGM Unpad adalah perempuan sehingga terjadi ketimpangan jumlah populasi yang cukup besar pada penelitian ini dimana laki-laki memiliki populasi yang lebih sedikit. Pelapisan atau proses coating terjadi secara alami pada lidah oleh karena sel-sel epitel terkelupas pada permukaan lidah. Namun, kegagalan dalam proses fisiologis ini dapat menyebabkan lidah dapat terlihat seperti memiliki lapisan plak tipis pada permukaan dorsal lidah atau yang disebut sebagai coated tongue. Coated tongue sering ditemukan terutama pada individu yang mengkonsumsi makanan lunak.

Mengacu pada area atau distribusi lapisan pada lidah, sebagian besar subjek memiliki skor 1 dan 2 dimana permukaan posterior lidah tertutup. Untuk hasil penilaian berdasarkan perubahan warna atau diskolorasi, sebagian besar sampel termasuk ke dalam skor 1 dimana lapisan tersebut berwarna putih atau kuning pucat. Tidak ada elaborasi lebih lanjut mengenai klasifikasi coated tongue di antara subjek penelitian dalam penelitian sebelumnya. Namun, dalam penelitian ini, subjek penelitian selanjutnya diklasifikasikan menurut klasifikasi Miyazaki. Secara fisiologis, akan ada lapisan kuning pucat di posterior lidah karena proses pencernaan di perut. Makanan yang dicerna akan difermentasi dan menghasilkan 'uap' yang menjadi bentuk kelembaban di lapisan. Pelapisan akan mulai menjadi lebih tebal di bagian posterior lidah dan secara bertahap menuju ujung lidah. ${ }^{11}$ Menurut pendapat peneliti, mahasiswa kedokteran gigi FKG Unpad sebagian besar memiliki skor 1 dan 2 kemungkinan dikarenakan waktu penelitian atau sampel yang diperoleh selama istirahat makan siang dan sisa-sisa makanan mungkin ada pada permukaan dorsal lidah dan faktor predisposisi lainnya yang dijelaskan lebih lanjut di bawah ini. Pernyataan ini dibuktikan dari hasil penelitian in dimana sebagian besar subjek penelitian memiliki skor 1 dan 2. Pernyataan sebelumnya juga secara visual terbukti ketika sebagian besar subjek penelitian memiliki lapisan kuning pucat di lidah. Hal ini mungkin terpicu karena adanya aktivitas fisiologis lambung selama pencernaan. Selain itu, variasi warna coated tongue juga dapat disebabkan oleh papilla filiformis lidah yang panjang dimana besar risiko untuk menjebak bakteri kromogenik, jamur dan pigmentasi makanan yang kemudian membuat lidah berubah warna.

Dalam penelitian ini, coated tongue memiliki beberapa faktor predisposisi seperti diet lunak, asupan obat-obatan seperti antibiotik, asupan air lebih sedikit dan asupan serat lebih sedikit. Hasil pengisian kuisioner menunjukkan bahwa sekitar 
$42,6 \%$ mahasiswa kemungkinan memiliki coated tongue karena diet lunak dan hal ini diduga karena keterbatasan waktu yang dimiliki mahasiswa FKG dan pola hidup instan dimana kemudian menyebabkan sampel memiliki kebiasaan menelan makanan cepat saji seperti roti dan bubur. Diet lunak adalah ketika seseorang mengkonsumsi makanan yang membutuhkan proses mengunyah minimum. Diet lunak dapat menyebabkan akumulasi puing-puing makanan pada permukaan lidah dan ketika tidak dibersihkan dengan benar, akhirnya menyebabkan lidah terlapisi. Menurut pendapat peneliti, kesibukan dan jadwal yang padat yang dimiliki para mahasiswa klinik FKG Unpad adalah alasan utama mengapa coated tongue hadir di sebagian besar sampel pada penelitian ini. Dalam penelitian ini, 5,9\%, atau 4 mahasiswa, memiliki coated tongue karena asupan obat. Antibiotik adalah contoh obat yang diketahui dapat memicu terbentuknya coated tongue. Antibiotik menghambat aksi bakteri dalam rongga mulut yang mengubah flora mikro dalam rongga mulut. Perubahan lingkungan ini akan menginduksi pertumbuhan ragi di rongga mulut, dan menyebabkan lidah tampak putih/coated. ${ }^{13}$ Selain itu, asupan air yang lebih sedikit dan serat makanan juga dapat menyebabkan coated tongue. Dalam penelitian ini, ditemukan sebanyak 26 mahasiswa $(38,2 \%)$ yang menyatakan bahwa mereka memiliki coated tongue karena kurangnya asupan air. Jumlah air yang cukup (delapan gelas air per hari) memainkan peran yang sama karena air dapat membersihkan dan menyiram semua partikel makanan yang mengendap di lidah dan karenanya menghasilkan lidah yang lebih bersih dan menghindari pembentukan coated tongue. ${ }^{13}$ Selain itu, sembilan mahasiswa $(13,2 \%)$ memiliki coated tongue karena kurangnya asupan serat. Gesekan antara sayuran hijau dan permukaan dorsal lidah membantu menghasilkan sifat membersihkan diri yang mencegah terjadinya. Karena itu, asupan serat dalam jumlah yang cukup juga penting. Singkatnya, coated tongue adalah hasil dari beberapa faktor predisposisi seperti diet lunak, asupan air lebih sedikit, asupan serat lebih sedikit dan juga obatobatan, dimana ini merupakan faktor risiko pembentuk debris pada permukaan dorsal lidah.

\section{SIMPULAN}

Menurut penelitian yang dilakukan di kalangan mahasiswa kedokteran gigi di FKG Unpad, sebagian besar sampel memiliki skor 2 untuk klasifikasi Miyazaki dan skor 1 untuk klasifikasi Gomez. Untuk faktor-faktor predisposisi, coated tongue kemungkinan terjadi pada sampel sebagian besar dikarenakan faktor diet lunak, diikuti oleh asupan air yang lebih sedikit, asupan serat yang lebih sedikit dan asupan obat-obatan.

\section{DAFTAR PUSTAKA}

1. Mosby. Mosby's Medical Dictionary. 9th ed. Elsevier; 2013. $1784 \mathrm{p}$.

2. Tortora GJ. Principles Of Anatomy and Physiology. 2012. 972 $974 \mathrm{p}$.

3. Neil S. Norton. Netter's Head and Neck Anatomy For Dentistry. 2nd ed. 2012. 380-383 p.

4. Reamy B V, Derby R, Col L, Bunt CW. Common Tongue Conditions in Primary Care SORT: KEY RECOMMENDATIONS FOR PRACTICE. 2010;81(5):627-34.

5. Kamala A Kamble, Sanketh S Guddad, Ajay G Nayak, Ashwinirani Suragimath ARS. Prevalence of Oral Mucosa Lesions in Western Maharashtra: A Prospective Study. J Indian Acad Oral Med Radiol. 2017;29(4):282-7.

6. Darwazeh, Azmi-Mohammad-Ghaleb A-AA. Tongue lesions in a Jordanian population. Prevalence, symptoms, subject's knowledge and treatment provided. Med Oral Patol Oral Cir Bucal. 2011;16(6):745-9.

7. Santosh Patil, Sumita Kaswan, Farzan Rahman and BD. Prevalence of tongue lesions in the Indian population. J Clin Exp Dent. 2013;5(3):128-32.

8. Ugar-Cankal D, Denizci S, Hocaoglu T. Prevalence of tongue lesions among Turkish schoolchildren. Saudi Med J [Internet]. 2005 Dec;26(12):1962-1967. Available from: http:// europepmc.org/abstract/MED/16380783

9. Nir Sterer MR. Breath Odors of Oral Origin (Oral Malodor). In Breath Odors. 2011. p. 5-11.

10. Ragunathan M. Prevalence of Tongue Lesions among Dental Students in Faculty of Dentistry Universitas Padjadjaran. Universitas Padjadran; 2019

11. J.Brandt DAG. CHAPTER 76 - The Upper Gastrointestinal Tract. In: Brocklehurst's Textbook of Geriatric Medicine and Gerontology. 2010. p. 608-25.

12. Brad W. Neville, Douglas D. Damm, Carl M. Allen ACC. Color Atlas of Oral and Maxillofacial Diseases. 2018. 12 p.

13. Floch MH. Netter's Gastroenterology. 3rd Edition. Elsevier; 2010. $107 \mathrm{p}$. 